argument for the effect of the sunlight, for in his experiments an eventual sunlight effect would be mixed with a very considerable variation of intensity distribution, discovered by me in 1923 (Phil. Mag., 46, p. $577 ; 1923$ ), which was measured accurately under the most favourable photographic conditions (see article on auroræ, "Handbuch der Physik", Bd. 25, p. 385). It was then found that the intensity of the auroral line relatively to that of the auroral nitrogen lines $(4709,4278,3914)$ diminished considerably with increase of height. The effect is clearly shown in Fig. 1, giving registerings of two spectrograms on the same plate corresponding to a difference of altitude of about $60 \mathrm{~km}$. For the lower limit, the auroral line 5577 gives a greater density than 4709 , while at the upper limit the densities are inversed. Quantitative measurements gave the result that $\frac{(a / b) \text { upper }}{(a / b) \text { lower }}=0.695$ on a pair of spectra from one plate, and $0 \cdot 76$ on a pair from a second plate; $a$ and $b$ are the intensity of the auroral line and that of one of the nitrogen lines respectively.

Now Størmer's spectra correspond to differences of altitude of $200 \mathrm{~km} .-300 \mathrm{~km}$., and from the variation with altitude alone we should, in the case considered by Størmer, expect to find $\frac{(a / b) \text { sunlit }}{(a / b) \text { shadow }}=$ about $0 \cdot 3$, which would mean a very great intensity variation. Thus, even if it had been possible from Størmer's material to conclude that the sunlit aurora gave a relatively weaker auroral line, this effect might be due merely to the altitude effect I discovered in 1923.

Oslo, Nov. 15.

L. VEGARD.

\section{A Haploid Enothera.}

A SINGLE haploid Enothera occurred this year in a culture of $F_{1}$ hybrids which were non-viable, and this result is of such interest as to deserve a separate record.

In 1927 reciprocal crosses were made between Enothera rubricalyx and $\alpha E$. eriensis, both of which have fourteen chromosomes. $G$. eriensis $\times$ rubricaly $x$ gave a uniform $F_{1}$ with the red pigmentation of rubricalyx and the small flowers of eriensis. They bred true in $F_{2}^{\prime}$ and were strongly patroclinous except in flower size.

The reciprocal cross, rubricaly $x \times$ eriensis, made at the same time, produced a potful of seedlings which were yellowish in colour, developed a little chlorophyll, and then promptly died when their stored nourishment was used up. The striking non-viability of this hybrid type led to a repetition of these crosses in 1928 with the same results. The rubricaly $x \times$ eriensis gave from one capsule 21 small and feeble seedlings, all of which died off simultaneously, showing a lethal effect. From another capsule, obtained by crossing different individuals of the same two species, 85 seedlings were obtained. They behaved in the same way as the preceding, except that two of the seedlings managed to survive for a time and one-lived long enough to be planted out. It reached maturity and belonged to a new type, very much dwarfed and completely sterile as regards pollen and seed production.

It was predicted that this plant might be a haploid, and such has proved to be the case, as it has only seven chromosomes in its somatic cells. The plant showed the red pigmentation of rubricalyx. Its leaves were small, narrow, and rather pointed, and these were regarded at first as resemblances to $\mathscr{E}$. eriensis ; but it seems more probable that these are characters pertaining to haploid rubricalyx.

As regards the origin of this haploid mutant, it appears to have developed parthenogenetically from a rubricalyx egg under the stimulus derived from the foreign pollen tubes of eriensis. The great bulk of the seedlings, which were non-viable, appear to have been true (diploid) hybrids with eriensis.

The first haploid sporophyte in higher plants was discovered by Blakeslee in 1922 in the offspring of Datura plants which had been subjected to low temperature at about the time of fertilisation. Other cases of haploids have since been found in Nicotiana, Triticum, Crepis, Solanum nigrum, and recently in the tomato. They have usually resulted, like the above, from crosses between two distantly related species with a high degree of interspecific sterility. In the present instance, the sterility appears to be complete when the cross is made one way, while the reciprocal cross produces plenty of viable seedlings.

$A$ full account of this haploid mutant will be published later.

King's College,

University of London, Dec. 2.

\section{The Perfect Elasticity of Wool.}

THE most striking property of the wool fibre is its ability always to return to its original length after stretching in cold water. If, however, a fibre is steamed in the strained position, it shows no tendency to return to its original length in cold water. So far as I am aware, it has hitherto been found impossible to induce such fibres to return to their original length, although partial recovery occurs on re-steaming in the absence of tension. During the course of another investigation, however, I have recently found that fibres which have taken a permanent set of the kind just described, recover the property of perfect elasticity in caustic soda solutions. For example, a fibre which had been stretched and steamed for 15 minutes at 47.4 per cent extension, returned to its original length in 14 minutes in $0.15 \mathrm{~N}$ caustic soda solution. Contraction does not cease when the original length is attained, but continues beyond this point until a real shrinkage of about 10 per cent of the original length is observed. The rate of recovery increases with the strength of the solution, but is measurable even in $0.01 \mathrm{~N}$ caustic soda. The discovery opens up a number of possibilities in regard to 'finishing' processes in the wool textile trade, but of even greater significance is the contribution which it makes to knowledge of the elastic phase in the wool fibre and the changes which it undergoes during stretching and steaming. Complete details of the results and conclusions of the investigation will be described in another place.

The University, Leeds, Nov. 28.

\section{Continents and Oceans.}

As the result of my letter on "Continents and Oceans ", which appeared in NATuRE for Nov. 30, several correspondents have directed my attention to Lothian Green's 'tetrahedral hypothesis'. This hypothesis was devised to explain why the continents have oceans at their antipodes, and Prof. J. W. Gregory has given an excellent account of it in his little book entitled "The Making of the Earth", published in 1912.

I am sorry that I had not seen Prof. Gregory's book before I wrote my letter, as it would have helped me to emphasise the point which I wished to make; for the object of my letter was not to describe new relationships between the continents and oceans, but to direct attention to the necessity for taking the relationships which I described into account when discussing Wegener's hypothesis. G. C. SIMPson. Meteorological Office,

Air Ministry, Kingsway, W.C.2, Dec. 5.

No. 3138 , VoL. 124] 